\title{
Avaliação do coping da dor em crianças com Anemia Falciforme
}

\author{
Evaluation of pain coping strategies in children \\ with sickle cell disease
}

\author{
Daniele de Souza GARIOLI' ${ }^{1}$ iD 0000-0001-6827-7979 \\ Kely Maria Pereira de PAULA² ID 0000-0001-9095-6556 \\ Sônia Regina Fiorim ENUMO²,3 (iD) 0000-0001-9038-6151
}

\section{Resumo}

O enfrentamento (coping) da dor desempenha um papel importante na adaptação à doença crônica e seus efeitos. Este estudo analisou o coping da Anemia Falciforme em 12 crianças com idade entre oito e dez anos, que frequentavam um Hospital Universitário de Vitória, Espírito Santo, pelo Instrumento Informatizado de Avaliação do Enfrentamento da Hospitalização e da Dor. Os resultados mostram que as estratégias de enfrentamento mais frequentes foram ruminação, solução de problemas e reestruturação cognitiva. Observa-se, assim, uma ativa busca de estratégias para a solução de problemas, procurando-se redirecionar o pensamento para aspectos mais positivos da situação estressante; contudo, a maior frequência da ruminação indica que as crianças estão controladas por aspectos negativos da doença, condição de risco para o desenvolvimento de transtornos de comportamento internalizante. Discute-se esta proposta de avaliação do coping da dor nessa população com base na Teoria Motivacional do Coping e suas contribuições para intervenções na área.

Palavras-chave: Anemia falciforme; Coping; Crianças; Dor.

\begin{abstract}
Pain coping strategies play an important role in adapting to chronic illnesses and their effects. This study analyzed the coping processes of 12 children with sickle cell disease, aged 8 to 10 years, treated at a University Hospital in Vitória, Espirito
\end{abstract}

$\nabla \nabla v$

1 Centro Universitário São Camilo. R. José Garioli, 5, Centro, 29300-350, Cachoeiro de Itapemirim, ES, Brasil. Correspondência para/Correspondence to: D.S. GARIOLI. E-mail: <danielegarioli@gmail.com>.

2 Universidade Federal do Espírito Santo, Departamento de Psicologia Social e do Desenvolvimento, Programa de Pós-Graduação em Psicologia. Vitória, ES, Brasil.

3 Pontifícia Universidade Católica de Campinas, Centro de Ciências da Vida, Programa de Pós-Graduação em Psicologia. Campinas, SP, Brasil. Artigo elaborado a partir da dissertação de D.S. GARIOLI, intitulada "O impacto da dor nas funções executivas e sua relação com as estratégias de enfrentamento em crianças com Anemia Falciforme”. Universidade Federal do Espírito Santo, 2011.

Apoio: Coordenação de Aperfeiçoamento de Pessoal de Nível Superior (Processo nº 481483/2009-8).

Como citar este artigo/How to cite this article

Garioli, D. S., Paula, K. M. P., \& Enumo, S. R. F. (2019). Avaliação do coping da dor em crianças com Anemia Falciforme. Estudos de Psicologia (Campinas), 36, el60079. http://dx.doi.org/10.1590/1982-0275201936e160079 
Santo, using a computerized tool for the assessment of pain coping strategies during hospitalization. The results showed that the most frequent coping strategies were rumination, problem solving and cognitive restructuring. We observed an active search for strategies to solve problems, seeking to divert attention from stressful circumstances to positive thoughts. However, the higher frequency of rumination indicates that children are controlled by negative emotions of the disease, which increases the risk for the development of internalizing disorders. The evaluation of pain coping strategies in this population was based on the Motivational Theory of Coping and its contribution to interventions in the field.

Keywords: Anemia, sickle cell; Coping; Children; Pain.

A Anemia Falciforme é a mais comum entre as doenças genéticas e entre as hemoglobinopatias, sendo a de maior prevalência no Brasil. No país, nascem, por ano, aproximadamente 3.500 crianças com Anemia Falciforme e 200 mil com o traço da doença, dos quais $20 \%$ não atingem os cinco anos de idade, devido a complicações, afetando entre 6\% a 10\% da população afrobrasileira (Ministério da Saúde, 2013). O quadro clínico, desde o nascimento, inclui anemia crônica, crises dolorosas, infecções, dactilite, crises de sequestros esplênicos (principal causadora de óbito), acidente vascular cerebral, complicações oculares e cálculo biliar. A dor, que pode ser crônica, com episódios que duram três meses ou mais, ou aguda e imprevisível, decorre da alteração das hemácias, em forma de foice, ocluindo pequenos vasos sanguíneos, seguindo-se o infarto nos tecidos. São exigidas constantes hospitalizações e consultas regulares. É, portanto, uma doença que afeta o desenvolvimento emocional, comportamental, cognitivo, acadêmico e social. Um tratamento medicamentoso eficaz tem sido feito com a Hidroxiureia (HU) (Sena, Vieira, \& Lyra, 2011) e, entre as medidas terapêuticas, existem múltiplas técnicas psicológicas, como, por exemplo, recreação, relaxamento, distração, musicoterapia, acupuntura, hipnose, biofeedback ${ }^{4}$ e psicoterapia de apoio, utilizando como base teórica, principalmente, a Terapia Cognitivo-Comportamental (Anie, 2005).

Apesar de ser um dos principais problemas de saúde pública no Brasil, com grande ônus financeiro e impacto social sobre a população afetada, ainda são poucos os estudos na área da Psicologia, especialmente no país (Dias \& Leite, 2014). Revisões da área mostram que as complicações psicológicas da Anemia Falciforme incluem estratégias inadequadas para lidar com a dor, qualidade de vida reduzida decorrente das restrições ao funcionamento cotidiano, ansiedade e depressão, bem como alterações neurocognitivas. O desamparo e a baixa autoestima resultam da dor constante, das hospitalizações e das perdas na escolarização das crianças (Anie, 2005; Barreto \& Cipolotti, 2014).

O impacto psicológico pode ser agrupado segundo as tarefas relacionadas à doença, o ajustamento aos sintomas e incapacidades, a manutenção de uma boa relação com os profissionais de saúde, e o manejo das consequências emocionais e sociais da doença (Anie, 2005). Analisando essas consequências psicológicas da Anemia Falciforme, em revisão de área, Anie (2005) identificou serem comuns as "tentativas de coping" (distração e aumento de atividade) e o "pensamento negativo/adesão passiva" (pensamentos e sentimentos negativos, junto com métodos psicológicos "passivos", mas úteis, recomendados por hematologistas, como descansar e tomar líquidos). O enfrentamento por "pensamento negativo/adesão passiva" se associa positivamente à severidade da dor e ao uso de serviços de saúde (consultas de emergência e hospitalizações, dentre outros). Esse tipo de coping também se relaciona a sintomas de depressão e ansiedade, dificultando a adaptação à Anemia Falciforme (Barakat, Schwartz, Simon, \& Radcliffe, 2007).

O melhor ajustamento psicológico na Anemia Falciforme está associado a menos estresse percebido no cotidiano, menos coping passivo e ao adequado funcionamento familiar, com menos conflitos e mais

\footnotetext{
$\boldsymbol{\nabla} \boldsymbol{\nabla} \nabla$
}

4 Método psicofísico voltado para o desenvolvimento de estratégias que alteram a atividade das funções corporais, que voluntariamente não seriam controladas. É um procedimento que visa tornar os comportamentos conscientes mediante técnicas de monitoramento, proporcionando controle por aprendizagem implícita e desenvolvendo a capacidade de autorregulação (Barnea, Rassis, Raz, Othmer, \& Zaidel, 2004). 
suporte (Anie, 2005). Em outras palavras, a avaliação do impacto deverá considerar variáveis relacionadas às peculiaridades da doença, bem como ao repertório de enfrentamento (coping) da criança (Anie, 2005; Motta \& Enumo, 2010). Esse é o tema do presente estudo - o coping da dor na Anemia Falciforme em crianças.

Analisado sob uma perspectiva desenvolvimentista e de autorregulação (Ramos, Enumo, \& Paula, 2015), o coping é entendido como "... a regulação da ação sob estresse", relacionada à "... 'forma como as pessoas mobilizam, guiam, manejam, energizam e direcionam o comportamento, a emoção e a orientação, ou como elas falham ao fazê-lo', sob condições estressantes" (Skinner \& Zimmer-Gembeck, 2007, p.122). Segundo essa Teoria Motivacional do Coping (TMC), considera-se como estressor qualquer evento que desafie ou ameace alguma das três necessidades básicas - de relacionamento, de competência e de autonomia (Skinner, Edge, Altman, \& Sherwood, 2003; Skinner \& Wellborn, 1994; Skinner \& Zimmer-Gembeck, 2016; Vasconcelos \& Nascimento, 2016). Nesse caso, a Anemia Falciforme, com suas limitações e riscos associados, é considerada um grande estressor (Anie, 2005). Diante desses eventos, a TMC considera que a pessoa pode lidar de uma forma mais adaptativa no médio e longo prazo, quando percebe o estressor como um desafio a essas necessidades básicas. Pode, então, apresentar respostas relacionadas a seis categorias de alta ordem (famílias de coping ou macrocategorias), como: Autoconfiança e Busca de Suporte (relacionamento), Resolução de Problemas e Busca de Informações (competência), Acomodação e Negociação (autonomia). A percepção de ameaça a essas necessidades básicas pode levar a respostas mal adaptativas classificadas em outras seis categorias: Delegação e Isolamento (relacionamento), Desamparo e Fuga (competência), Submissão e Oposição (autonomia). Para cada uma dessas 12 macrocategorias de coping, várias estratégias de enfrentamento e comportamentos podem ser incluídas funcionalmente. Por exemplo, a criança pedir ajuda à mãe quando está com dor (instância de coping) faz parte da estratégia de enfrentamento busca por conforto/busca de ajuda, que, por sua vez, se inclui na categoria de coping de alta ordem Busca de Suporte.

Essas categorias de alta ordem de coping e algumas estratégias de enfrentamento a elas relacionadas foram descritas no estudo de Motta e Enumo (2010) com crianças com câncer, com base no trabalho de Skinner e Zimmer-Gembeck (2007), a saber:

1) Percepção de desafio ou ameaça à necessidade de competência - (a) solução de problemas, que abrange a ação instrumental voltada à solução dos desafios, com o estabelecimento de estratégias, planejamento, análise lógica, esforço, persistência e determinação; (b) busca de informações, que envolve esforços para aprender mais sobre o que produz o estresse e como resolver ou evitar; (c) esquiva (fuga), que inclui esforços para manter-se distante daquilo que leva ao estresse; e (d) desamparo, que inclui passividade, confusão, interferência ou exaustão cognitiva, desânimo e pessimismo.

2) Percepção de desafio ou ameaça à necessidade de relacionamento ou de pertença - (a) busca de conforto (ou de suporte), no qual a pessoa procura apoio junto a pais, profissionais, Deus, amigos, dentre outras fontes, com o objetivo de aconselhamento, conforto e contato; (b) afastamento social (isolamento), em que as ações do indivíduo o levam a se manter afastado das pessoas ou evitar que elas tomem conhecimento de sua situação estressante e seus efeitos psicológicos; e (c) delegação, que inclui estratégias relativas à dependência, busca mal adaptativa por ajuda, reclamações, queixas, resmungos e autopiedade.

3) Percepção de desafio ou ameaça à necessidade de autonomia - (a) acomodação, incluindo as estratégias de enfrentamento de distração, com ações relativas ao envolvimento em atividades prazerosas, como forma de lidar com algo que causa estresse; reestruturação cognitiva, que significa a tentativa de ver o lado positivo da situação adversa, por meio de mudanças de pensamento; e regulação emocional, que inclui esforços para influenciar e expressar as emoções de modo apropriado, condizentes com o momento ou o ambiente; (b) negociação, que se refere a tentativas ativas de fazer um acordo entre as próprias necessidades e as restrições impostas pela situação estressante; (c) ruminação (submissão), que se refere ao foco passivo e repetido nos aspectos negativos daquilo que afeta o indivíduo; e (d) oposição, que envolve comportamentos 
de projeção, agressão, reações de raiva, descarga e atribuição de culpa a outras pessoas. Essas categorias de alta ordem e suas estratégias de enfrentamento também foram adotadas neste estudo.

Oliveira, Paula e Enumo (2017), aplicando essas categorias segundo a TMC em estudo sobre intervenção no coping da Anemia Falciforme, identificou maior frequência de estratégias de enfrentamento de ruminação, planejamento de estratégias, busca de conforto, aceitação, regulação emocional e passividade. Nas categorias de alta ordem de coping identificou Acomodação, seguida de Submissão e Resolução de Problemas. Outros estudos nacionais aplicando a TMC na área da saúde (Garioli, 2016; Hostert, Motta, \& Enumo, 2015; Lima, Barros, \& Enumo, 2014; Moraes \& Enumo, 2008; Motta \& Enumo, 2010; Motta et al., 2015; Oliveira et al., 2017) também identificaram essas categorias e estratégias de enfrentamento, com destaque para a ruminação, em outros quadros clínicos.

Considerando a necessidade de mais estudos nacionais sobre questões psicológicas na Anemia Falciforme, e com o objetivo de contribuir para o estudo do coping infantil na área da Psicologia Pediátrica, este trabalho tem como foco descrever e analisar o coping da dor da Anemia Falciforme em crianças com a doença.

\section{Método}

\section{Participantes}

Compuseram a amostra de conveniência deste estudo 12 crianças ( 7 meninas) portadoras de Anemia Falciforme e suas mães. As crianças, com idade entre 8 anos e 10 anos e 11 meses $(M=9 ; D P=1,08)$, frequentavam o $2^{\circ}, 3^{\circ}, 4^{\circ}$ e $5^{\circ}$ ano de escolas públicas e recebiam atendimento em ambulatório de Hematologia Pediátrica de um Hospital Universitário de Vitória (ES). No Estado do Espírito Santo há aproximadamente um caso a cada 1.800 nascimentos ao ano, sendo que $2 \%$ correspondem ao traço falciforme, ou seja, o indivíduo possui apenas um gene do par da doença, sendo, portanto, heterozigoto, assim, não desenvolve a doença, podendo somente transmiti-la aos filhos (Ministério da Saúde, 2013).

Os seguintes critérios de inclusão foram aplicados: (1) diagnóstico de Anemia Falciforme dado por um hematologista pediátrico segundo os critérios do CID 10 (CID.10: D57.0 - Anemia Falciforme com crise - Doença Hb-SS com crise) e estar em atendimento ambulatorial; e (2) idade entre 8 anos e 10 anos e 11 meses, com repertório verbal para emitir informações acerca da situação da doença e compreender as atividades propostas. Como critério de exclusão foram consideradas as crianças com comprometimento motor que impedisse o manuseio dos instrumentos de avaliação psicológica.

Todos os participantes assinaram o Termo de Consentimento Livre e Esclarecido e de Assentimento. A pesquisa foi aprovada pelo Comitê de Ética em Pesquisa (CEP/UFES), sob o nº 092/10, bem como pelo Comitê de Ética do hospital.

As crianças participavam de um grupo de apoio desenvolvido por três pediatras hematologistas e uma enfermeira, vinculado à Associação de Portadores de Anemia Falciforme do Espírito Santo, com encontros realizados a cada semana no ambulatório do hospital, geralmente nos dias de consulta médica. O grupo de apoio tinha por objetivo fornecer esclarecimentos aos pais e portadores sobre a sintomatologia, evolução e tratamento da doença. No entanto, esses atendimentos não eram acompanhados por psicólogos ou terapeutas, sendo um grupo exclusivo para elucidar dúvidas médicas.

A coleta de dados foi realizada no ambulatório do referido hospital, sendo este um dos Centros de Referência no atendimento de pessoas portadoras de Anemia Falciforme no Espírito Santo, seguindo

4 o protocolo clínico e as diretrizes terapêuticas para tratamento da doença, em consonância com a Política 
Nacional de Atenção às Pessoas com Doença Falciforme e outras Hemoglobinopatias, proposta pelo Ministério da Saúde em 2005. Os Centros de Referência seguem um protocolo nacional e realizam avaliação física, dentária e nutricional em crianças com tal diagnóstico, assim como exame oftalmológico, esquema profilático de penicilina, aconselhamento genético e estudos de função cardíaca e renal, com a seguinte periodicidade: (a) exame mensal em idade inferior a seis meses; (b) exame bimestral, em idade superior a seis meses; (c) exame trimestral de um a cinco anos; e (d) exame quadrimestral, para idade superior a cinco anos.

\section{Instrumentos}

Para caracterizar a amostra, além da análise dos prontuários, foi realizada uma anamnese adaptada (Carretoni Filho \& Prebianchi, 1994) com as mães, permitindo o levantamento de informações sobre a criança, sua família, histórico da doença e crises álgicas.

O nível de dor percebido pela criança foi avaliado pela Escala Faces de Dor - Revisada - EF-R (Poveda, Silva, Passareli, Santos, \& Linhares, 2010), composta por seis diferentes figuras de expressões faciais, que variam de face sem dor até dor insuportável, sendo: $0=$ sem dor; $2=$ dor mínima; $4=$ dor leve; $6=$ dor moderada; 8 = dor forte; e $10=$ dor extrema.

Para a identificação das estratégias de enfrentamento, foi aplicado o Instrumento Informatizado de Avaliação do Enfrentamento da Hospitalização adaptado para dor (AEHcomp-Dor), com adaptação de Oliveira et al. (2017) a partir do AEHcomp (Moraes \& Enumo, 2008; Motta \& Enumo, 2010). O AEHcomp-Dor contém vinte cenas ilustradas com desenhos coloridos, com uma versão para meninos e outra para meninas. As cenas caracterizam situações que permitem identificar o que as crianças fazem, pensam e sentem sobre sua experiência dolorosa, ou seja, representam as instâncias de coping, incluindo comportamentos mais adaptativos à hospitalização, como brincar, assistir TV, cantar e dançar, rezar, estudar, conversar, ouvir música, ler gibi, tomar remédio, buscar informações, e outros menos adaptativos, como chorar, brigar, esconder-se, ficar triste, desanimar, fazer chantagem, pensar em fugir, sentir culpa, sentir medo e pensar em milagre. Além dessas vinte cenas, há um inquérito sobre as justificativas dadas às respostas escolhidas pela criança. Por exemplo, na cena "brincar", questiona-se por que a criança brinca para enfrentar a dor, ou, na cena "ficar triste", se ela se sente triste por ter que lidar com a dor. Em cada cena a resposta permite mais de uma justificativa. Assim, para um mesmo comportamento, várias estratégias de enfrentamento podem ser relacionadas, ou seja, em um relato é possível identificar mais de uma estratégia de enfrentamento.

Com base nas respostas a cada cena, foi feito o cálculo da média de comportamentos relatados pela criança para enfrentar a dor. O cálculo é realizado atribuindo-se um peso a toda resposta em cada cena ( não $=0$; um pouco $=1$; às vezes $=2$; quase sempre $=3$; e sempre $=4$ ), totalizando o escore máximo de oitenta pontos, considerando haver vinte cenas.

\section{Procedimentos}

Antes da aplicação do AEHcomp-Dor, todas as crianças responderam à escala visual de dor, com objetivo de identificar se, naquele momento, sentiam algum tipo de dor que impossibilitasse a avaliação. Caso a criança apresentasse nível de dor de "moderada" a "extrema" (níveis de 6 a 10), seria, então, encaminhada ao serviço ambulatorial para tratamento da dor e, posteriormente, convidada a participar de atividades lúdicas, caso desejasse. Uma segunda sessão seria marcada, repetindo-se o mesmo procedimento. Após a aplicação da escala de dor, foi aplicado o AEHcomp-Dor, individualmente, pela pesquisadora com treino anterior no instrumento e formação em Psicologia. Essa atividade teve duração média de trinta minutos e toda a aplicação foi gravada e transcrita na íntegra, para posterior análise. 
De início, foi feita a análise da frequência de respostas dadas em cada cena (comportamentos). As gravações das justificativas das crianças em cada cena foram transcritas e categorizadas, permitindo analisar suas estratégias de enfrentamento segundo as necessidades básicas envolvidas: (a) competência (solução de problemas, busca de informações, esquiva e desamparo); (b) relacionamento (busca de conforto, afastamento social e delegação); e (c) autonomia (distração, regulação emocional, reestruturação cognitiva, negociação, ruminação e oposição).

Devido à especificidade da amostra, a análise de dados do AEHcomp-Dor considerou o fato de que os pais são orientados pelos profissionais de saúde a deixar as crianças em repouso durante as crises álgicas. Na análise dos relatos, a justificativa dada pela criança para "não brincar" - porque a agitação pode causar mais dor - podia ser interpretada, por exemplo, como uma ação que visava à solução de problemas (não ter a crise de dor) e não como uma distração, que é normalmente a função do brincar.

Calculou-se o índice de concordância das classificações das estratégias de enfrentamento e justificativas das crianças no AEHcomp-Dor entre dois juízes independentes, para garantir a fidedignidade, adotando-se o valor $\geq 70 \%$ como suficiente para atribuir confiabilidade aos registros (Fagundes, 1982). Para isso, foram selecionados (por sorteio) dados de três das 12 crianças participantes do estudo ( $25 \%$ da amostra). A análise das categorias de enfrentamento apresentou o valor médio de concordância de $82 \%$ (74\% - 91\%), indicando um bom nível de fidedignidade dos dados.

\section{Resultados}

A anamnese realizada com as mães e o levantamento de prontuários médicos permitiram compor o perfil sociodemográfico e clínico dos participantes. Metade das crianças da amostra $(n=6)$ estava no $2^{\circ}$ ano do Ensino Fundamental, havendo três no $3^{\circ}$ ano, duas no $4^{\circ}$ ano e uma no $5^{\circ}$ ano. A escolaridade das mães variou de Ensino Fundamental Completo $(n=6)$ a Ensino Médio Completo $(n=6)$, sendo que a principal atividade ocupacional relatada foi a "do lar" $(n=9)$. Somente uma das mães tinha vínculo formal de emprego. Com relação ao perfil clínico do grupo, para cinco crianças, o diagnóstico foi realizado no primeiro ano de vida e duas no segundo ano, a maioria por meio do "teste do pezinho". Todas as crianças já tinham sido hospitalizadas devido a crises álgicas ou outros problemas decorrentes da Anemia Falciforme, por um período de internação que variou de 2 a 15 dias. Para controle da dor, a maioria $(n=8)$ utilizava a Hidroxiureia $(H U)$ havia um ano e, para este subgrupo, após o início do tratamento, não houve mais internações, de forma que, quando as crises álgicas ocorriam, eram de fácil manejo, não requerendo internação. No período da coleta de dados, segundo o relato das mães, em casa, as crises de dor estavam controladas e sem maiores intercorrências médicas.

As cenas com maior frequência de respostas no AEHcomp - "tomar remédio", "rezar" e "assistir TV" - correspondem a estratégias de enfrentamento mais adaptativas, no caso, solução de problemas (tomar remédio), distração (ver TV) e busca de conforto (rezar), atendendo às necessidades de competência, autonomia e relacionamento, respectivamente.

Os comportamentos menos relatados foram "pensar em fugir" e "esconder-se", relacionados ao coping de evitação ou esquiva (Fuga), e os comportamentos "sentir raiva" e "fazer chantagem", relativos ao coping de Oposição e Negociação, respectivamente, ambas estratégias de enfrentamento indicativas de ameaça à necessidade de autonomia (Figura 1).

A partir das justificativas apresentadas pelas crianças às respostas dadas no AEHcomp-Dor, foram identificadas 251 estratégias de enfrentamento, sendo as mais frequentes a ruminação ( $n=57 ; 22,7 \%)$, a

6 solução de problemas ( $n=56 ; 22,3 \%)$ e a reestruturação cognitiva $(n=38 ; 15,1 \%)$ (Figura 2$)$. 


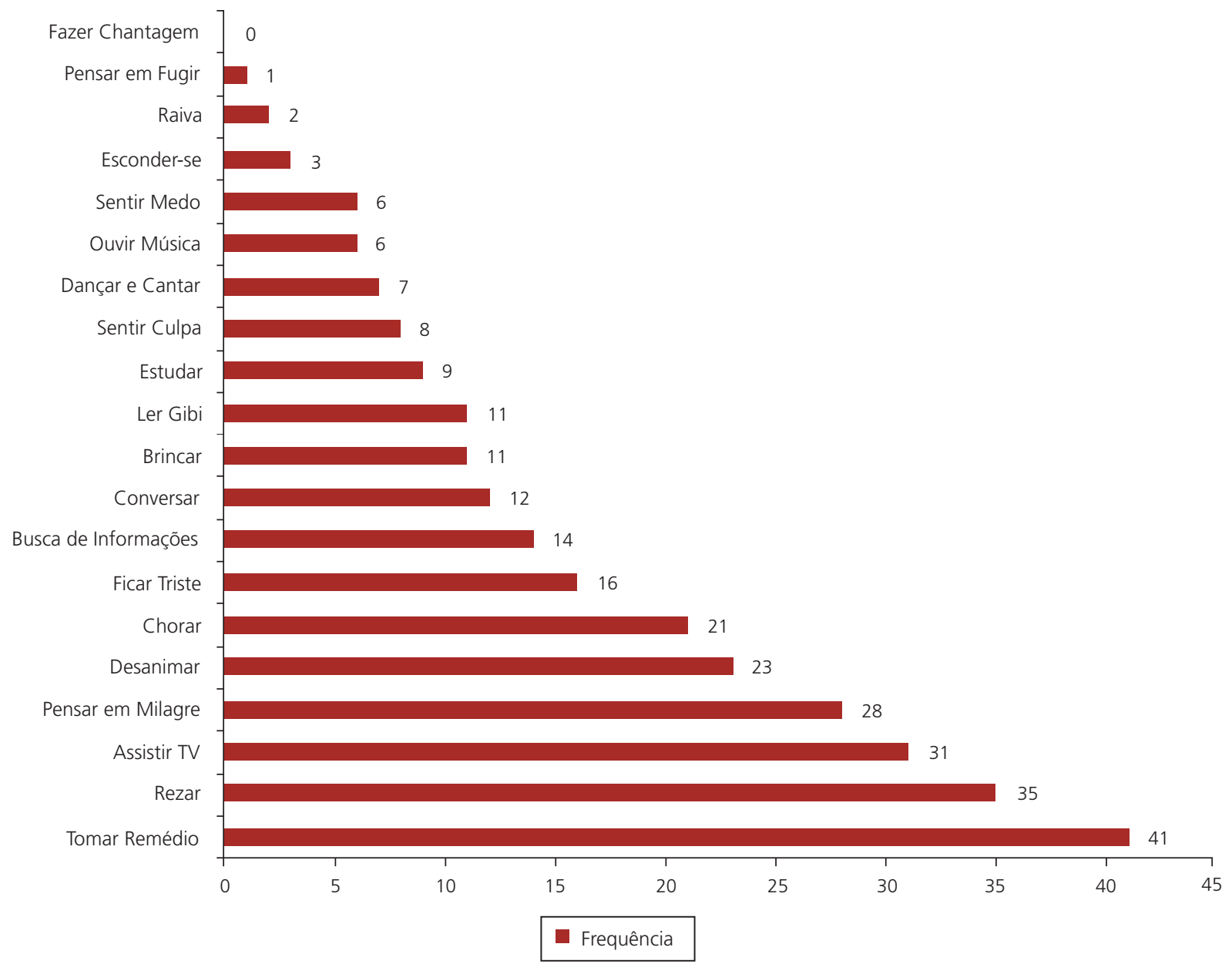

Figura 1. Frequência de comportamentos de enfrentamento da dor relatados por crianças com Anemia Falciforme no AEHcomp-Dor ( $N=285)$.

A estratégia de enfrentamento de ruminação é funcionalmente um coping de submissão diante da percepção de ameaça à necessidade de autonomia, sendo uma resposta com desfechos mal adaptativos no médio e longo prazo. Foi a mais relatada pelas crianças e pode ser identificada em justificativas dadas à resposta de não brincar: "Porque não dá pra aguentar a dor, dói muito" ( $C 5$, menino, 8 anos e 2 meses, Cena: Brincar). "Porque eu não tenho ânimo, dói demais" (C11, menina, 10 anos e 2 meses, Cena: Brincar).

A segunda estratégia de enfrentamento mais frequente foi a solução de problemas, indicativa de uma percepção de desafio à necessidade de competência, ilustrada pelas justificativas para não se esconder ou aceitar tomar o remédio:

Porque se eu me esconder, não vai adiantar nada; se eu falar para a mamãe, ela vai me ajudar (C10, menino, 8 anos e 8 meses, Cena: Esconder-se).

Porque depois que toma remédio, fica bom. Eu me sinto bem depois (C4, menino, 8 anos e 8 meses, Cena: Tomar remédio).

A reestruturação cognitiva é uma resposta de acomodação à situação, em que o estressor é percebido como um desafio à necessidade de autonomia. Foi a terceira estratégia de enfrentamento mais identificada nos relatos das crianças, em geral, associada à solução de problemas: 


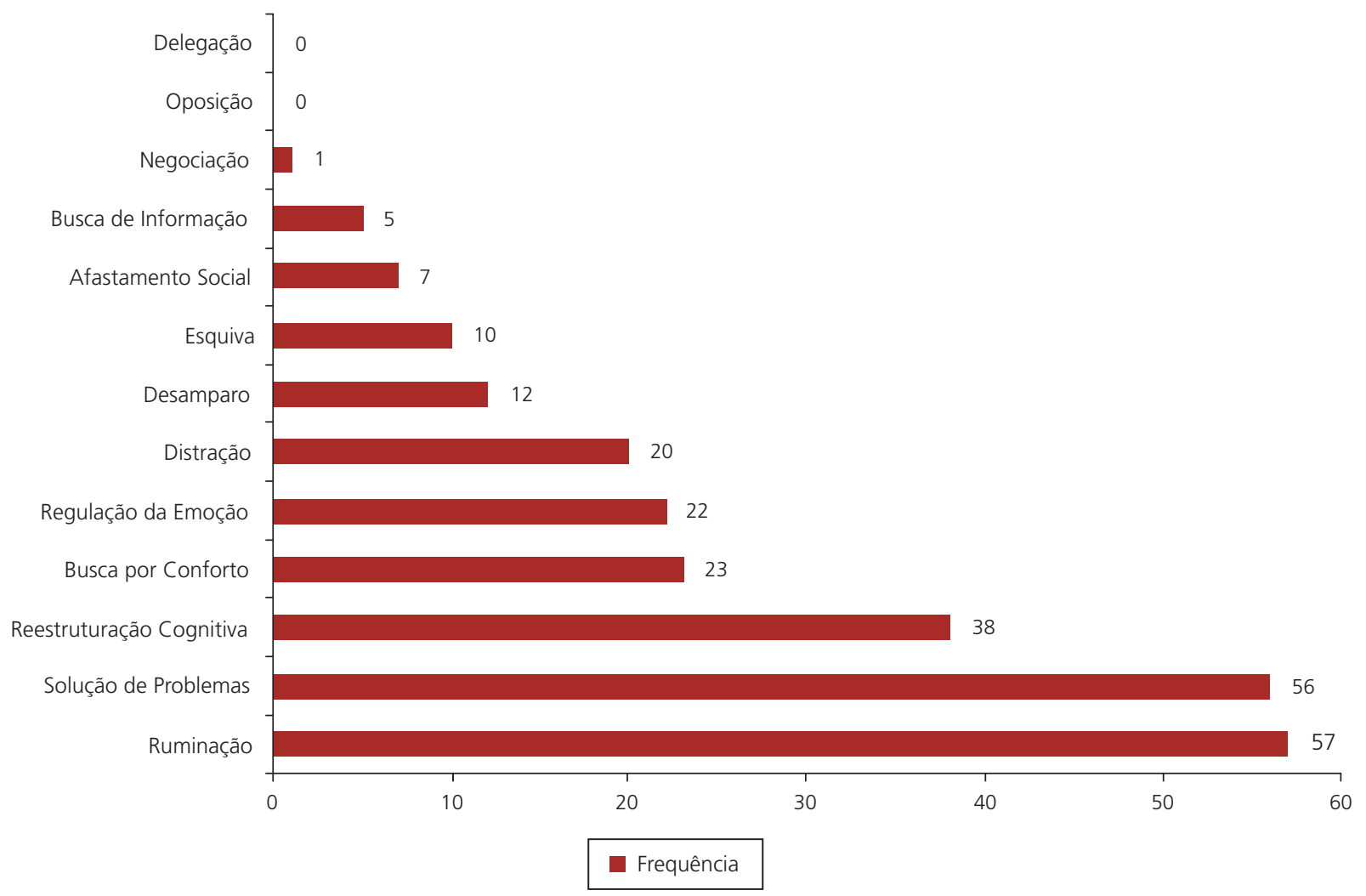

Figura 2. Frequência de estratégias de enfrentamento da dor apresentadas por crianças com Anemia Falciforme no $A E H c o m p-D o r(N=251)$.

Porque não adianta ficar com raiva (reestruturação cognitiva), a dor vai melhorar com o remédio! (solução de problemas) (C4, menino, 8 anos e 8 meses, Cena: Sentir raiva).

Na maioria das justificativas do grupo, outras estratégias de enfrentamento também estavam associadas à estratégias de enfrentamento de solução de problemas, como no exemplo:

Eu brinco porque a dor melhora (solução de problemas) e eu esqueço a doença e a dor (distração) (C3, menino, 8 anos e 8 meses, Cena: Brincar).

A busca de informações, o afastamento social e a negação, relacionadas às necessidades de competência, relacionamento e de autonomia, respectivamente, foram as estratégias de enfrentamento menos relatadas pelo grupo. Já a delegação e a oposição não foram identificadas em nenhum relato.

\section{Discussão}

As crianças com Anemia Falciforme desta amostra lidam com a dor por meio de estratégias de enfrentamento relacionadas à ruminação e à solução de problemas, seguidas pela reestruturação cognitiva, a busca de conforto, a regulação emocional e a distração. Em outros termos, percebem a dor como um estressor que limita sua autonomia, não conseguindo lidar de forma adaptativa, vindo a se submeter, o que gera reações de ruminação. Há, porém, outras respostas mais adaptativas, em que esse estressor, a dor, é percebido como um desafio às três necessidades básicas - de competência (solução de problemas), de autonomia (reestruturação cognitiva, regulação emocional e distração) e de relacionamento (busca de conforto). No geral, observa-se que a dor é uma ameaça ou um desafio, transformando-se em condição 
estressora, especialmente para a autonomia dessas crianças. Esse perfil foi encontrado por Oliveira et al. (2017), usando o mesmo instrumento (AEHcomp) em 11 crianças com Anemia Falciforme - a ruminação, seguida pela solução de problemas e a reestruturação cognitiva foram as estratégias de enfrentamento mais frequentes.

A ruminação também foi identificada com a aplicação do AEHcomp (Motta \& Enumo, 2010) em crianças com outras doenças crônicas - no câncer (Lima et al., 2014; Hostert et al., 2015; Motta \& Enumo, 2010) e em crianças hospitalizadas por outros problemas médicos (Carnier, Padovani, Perosa, \& Rodrigues, 2015; Moraes \& Enumo, 2008). Na literatura internacional ocorre o mesmo (Anie, 2005; Barakat et al., 2007). A ruminação compreende relatos indicativos de um foco passivo e repetitivo nos aspectos negativos da situação, com ênfase nos danos e perdas da situação estressante. É uma estratégia de enfrentamento considerada de risco, pois pode precipitar um quadro de depressão, prejudicando a adesão ao tratamento e afetando a evolução clínica do caso (Barakat et al., 2007). É também uma estratégia de enfrentamento associada a relatos indicativos de perdas impostas pela hospitalização, como o afastamento de familiares e amigos e o abandono das atividades cotidianas, tais como brincar na rua ou ir à escola. Transtornos associados, como a depressão e a ansiedade, também resultam da incerteza acerca do futuro, principalmente se a internação ultrapassar cinco dias (Dias, Baptista, \& Baptista, 2003), como ocorre em crianças com Anemia Falciforme. Nesse sentido, julga-se importante propor intervenções psicológicas com foco em estratégias de enfrentamento mais adaptativas para essa população, no sentido de minimizar os efeitos da ruminação, a exemplo da intervenção feita por Oliveira et al. (2017).

Apesar da alta frequência da ruminação, as outras cinco estratégias de enfrentamento mais frequentes nesta amostra são consideradas mais adaptativas, segundo a proposição da TMC (Skinner et al., 2003; Skinner \& Wellborn, 1994), demonstrando, assim, que essas crianças procuram redirecionar o pensamento para os aspectos mais positivos da situação estressante. Esses resultados sugerem que a relação entre a doença crônica e o tipo de enfrentamento não pode ser entendida como uma relação direta de causa e efeito, mas como um processo dinâmico, que exige a identificação de fatores capazes de influenciar a presença de uma dada estratégia. É preciso identificar os mecanismos protetores nos diferentes contextos nos quais a criança está inserida, capazes de minimizar e ou até mesmo neutralizar os efeitos do potencial risco ao desenvolvimento (Coletto \& Câmara, 2009; Klein \& Linhares, 2007).

Entre os fatores que podem ser ativados para minimizar esse risco, está o suporte social, geralmente disponível no próprio contexto da criança (Anie, 2005). Dessa forma, a redução dos efeitos dos riscos no desenvolvimento infantil também depende do ambiente e, por conseguinte, das mediações oferecidas a essa criança (Dias \& Leite, 2014; Klein \& Linhares, 2007). O suporte da equipe de saúde e os encontros entre pacientes e familiares desses participantes devem ter relações com as estratégias de enfrentamento adaptativas identificadas.

Pode-se considerar que a combinação entre diferentes estratégias de enfrentamento confere à criança mais recursos de enfrentamento do que a presença de uma única forma predominante de lidar com o agente estressor (Lima et al., 2014). Por sua vez, esta condição influenciará a autoavaliação do tipo de enfrentamento, em que a pessoa irá analisar a eficácia de suas ações (Skinner et al., 2003). É preciso ressaltar que, no contexto das doenças crônicas, sobremodo na Anemia Falciforme, o estressor (a dor) é de difícil controle e, muitas vezes, não poderá ser modificado, somente controlado por meio de intervenções farmacológicas e não farmacológicas. Dessa forma, são úteis novos processos de autorregulação para seu enfrentamento, como a adoção de estratégias mais adaptativas, como a solução de problemas e a reestruturação cognitiva.

Os principais comportamentos apresentados por essas crianças com Anemia Falciforme para enfrentar a dor, como "tomar remédio", "rezar" e "assistir TV", também foram frequentes em outras pesquisas sobre enfrentamento em crianças utilizando o AEH (Carnier et al., 2015; Lima et al., 2014; Motta et al., 2015). 
Esses dados mostram a importância de adotar, além do uso de medicamentos, condutas não farmacológicas para o tratamento da dor, como as técnicas de distração. As revisões de literatura mostram que esse tipo de conduta tem obtido resultados relevantes no tocante ao controle da doença, adesão ao tratamento, melhoria na qualidade de vida e enfrentamento da moléstia (Anie, 2005; Dias, Oliveira, Enumo, \& Paula, 2013).

Todavia, é importante ressaltar que atividades de distração, como "brincar" e "conversar", frequentemente empregadas pelas crianças no enfrentamento de situações adversas (Carnier et al., 2015; Lima et al., 2014), foram pouco frequentes nesta amostra. A justificativa apresentada centrou-se no fato de que, em momentos de crises álgicas, brincar ou realizar atividades cansativas pode desencadear ou potencializar a dor e, por isso, a maioria dos participantes prefere ficar quieto e sozinho. A dor crônica ou os frequentes episódios agudos de dor, como ocorre na Anemia Falciforme, além da consequente hospitalização, têm sido apontados como eventos de potencial risco para o desenvolvimento de problemas comportamentais e sociais em crianças (Von Baeyer et al., 2014). Estudos apontam que crianças ainda vivenciam desnecessariamente experiências dolorosas dado o manejo inadequado da dor (Stevens et al., 2014). Desse modo, o processo de avaliação do coping deverá considerar tanto a natureza da doença quanto os recursos bem-sucedidos já empregados pelo grupo no enfrentamento dessa condição.

Tendo em vista que a literatura aponta que as estratégias usadas para lidar com a doença e a dor desempenham um papel importante na adaptação à doença e aos seus efeitos (Anie, 2005), foi relevante analisar as estratégias de enfrentamento da situação dolorosa de crianças diagnosticadas com Anemia Falciforme. Tomando por base tais considerações e os resultados obtidos nas pesquisas sobre enfrentamento desenvolvidas no Brasil (Carnier et al., 2015; Moraes \& Enumo, 2008; Motta \& Enumo, 2010) e em Portugal (Lima et al., 2014), pode-se afirmar que o AEHcomp mostrou-se adequado para a compreensão e avaliação do enfrentamento no grupo de portadores de Anemia Falciforme. Foi possível coordenar a análise, relacionando as principais estratégias de enfrentamento, por exemplo, a solução de problemas, a busca de conforto, a distração, a reestruturação cognitiva e a ruminação (Skinner et al., 2003), com os diferentes comportamentos (instâncias de coping), no caso "tomar remédio", "rezar" e "assistir TV".

Em termos metodológicos, destaca-se a vantagem de se realizar uma avaliação psicológica em um formato computadorizado. O AEHcomp-Dor tem uma apresentação lúdica, motivadora para as crianças, facilitando a coleta de dados sobre a experiência do enfrentamento da dor, em uma situação estruturada de pesquisa. Os dados obtidos são consistentes com os resultados de pesquisas que utilizaram o mesmo instrumento (Carnier et al., 2015; Lima et al., 2014; Moraes \& Enumo 2008; Motta \& Enumo, 2010). Todavia, novos estudos são necessários para a avaliação do coping da dor, com a inclusão de cenas que representem outros comportamentos pertinentes à rotina de crianças com diagnóstico de Anemia Falciforme, como ficar quieto, beber água, dormir e ir ao hospital para tratamento. Além disso, devido à falta de instrumentos padronizados para a população brasileira, é relevante a padronização do instrumento, conforme feito para o AEH por Garioli (2016).

Partindo do pressuposto de que o modo como a criança percebe cognitivamente sua doença e se ajusta a essa situação depende de aspectos da doença, da própria criança e de seu contexto familiar (Coletto \& Câmara, 2009), e considerando as limitações deste estudo quanto à generalização dos dados (devido ao tamanho da amostra), considera-se importante, como direção para futuras pesquisas, uma análise mais abrangente sobre as relações entre coping e outras variáveis socioemocionais envolvidas na trajetória de dor da criança com Anemia Falciforme e sua família. Deverão ser considerados o estilo parental, os níveis de estresse, de ansiedade e de depressão das crianças e de seus cuidadores, bem como os tipos de suporte social oferecidos e percebidos nos diversos contextos, como a escola e o hospital. Certamente, esses estudos poderão ajudar na elaboração de intervenções dirigidas à população pediátrica com dor crônica, mediante o desenvolvimento de estratégias mais adaptativas frente às limitações da doença. 
Por fim, este estudo contribuiu para a área da Psicologia Pediátrica no país, fornecendo uma proposta de avaliação do coping infantil da Anemia Falciforme, em uma perspectiva motivacional, identificando as principais estratégias de enfrentamento da doença e da dor, segundo relato das próprias crianças. Esses dados podem subsidiar futuras intervenções psicológicas com essa população.

\section{Colaboradores}

Todos os autores contribuíram na análise, interpretação dos dados, discussão dos resultados, revisão e aprovação da versão final do artigo.

\section{Referências}

Anie, K. A. (2005). Psychological complications in sickle cell disease. British Journal of Haematology, 129(6), 723-729. http://dx.doi.org/10.1111/j.1365-2141.2005.05500.x

Barakat, L. P., Schwartz, L. A., Simon, K., \& Radcliffe, J. (2007). Negative thinking as a coping strategy mediator of pain and internalizing symptoms in adolescents with sickle cell disease. Journal of Behavioral Medicine, 30(3), 199-208. http://dx.doi.org/10.1007/s10865-007-9103-x

Barnea, A., Rassis, A., Raz, A., Othmer, S., \& Zaidel E. (2004). Effects of neurofeedback on hemispheric attention networks. Brain and Cognition, 59(3), 314-321. http://dx.doi.org/10.1016/j.bandc.2004.05.008

Barreto, F. J. N., \& Cipolotti, R. (2014). Sintomas depressivos em crianças e adolescentes com anemia falciforme. Jornal Brasileiro de Psiquiatria, 60(4), 277-283.

Carnier, L. E., Padovani, F. H. P., Perosa, G. B., \& Rodrigues, O. M. P. R. (2015). Estratégias de enfrentamento em crianças em situação pré-cirúrgica: relação com idade, sexo, experiência com cirurgia e estresse. Estudos de Psicologia (Campinas), 32(2), 319-330. http://dx.doi.org/10.1590/0103-166X2015000200015

Carretoni Filho, H., \& Prebianchi, H. B. (1994). Exame clínico psicológico (Anamnese). Campinas: Editorial Psy.

Coletto, M., \& Câmara, S. (2009). Estratégias de coping e percepção da doença em pais de crianças com doença crónica: o contexto do cuidador. Diversitas: Perspectivas en Psicologia, 5(1), 97-110.

Dias, R. R., Baptista, M. N., \& Baptista, A. S. D. (2003). Enfermaria de pediatria: avaliação e intervenção psicológica. In M. N. Baptista \& R. R. Dias (Orgs.), Psicologia hospitalar: teorias, aplicações e casos clínico (pp. 53-73). Rio de Janeiro: Guanabara Koogan.

Dias, T. L., \& Leite, L. L. G. (2014). Rede de apoio social e afetivo e estratégias de enfrentamento na doença falciforme: um olhar sobre a pessoa e a família. Psicologia em Revista, 20(2), 353-373.

Dias, T. L., Oliveira, C. G. T., Enumo, S. R. F., \& Paula, K. M. P. (2013). A dor no cotidiano de cuidadores e crianças com anemia falciforme. Revista Psicologia USP, 24(3), 391-411. http://dx.doi.org/10.1590/S0103-65642013000300003

Fagundes, A. J. F. M. (1982). Descrição, definição e registro de comportamento. São Paulo: Edicon.

Garioli, D. S. (2016). Escala de Coping da Hospitalização (COPE-H): processo de adaptação (Tese de doutorado não-publicada). Universidade Federal do Espírito Santo, Vitória.

Hostert, P. C. C., Motta, A. B., \& Enumo, S. R. F. (2015). Coping da hospitalização em crianças com câncer: a importância da classe hospitalar. Estudos de Psicologia (Campinas), 32(4), 627-639. http://dx.doi.org/10.1590/0103-16 6X2015000400006

Klein, V. C., \& Linhares, M. B. M. (2007). Temperamento, comportamento e experiência dolorosa na trajetória de desenvolvimento da criança. Paidéia, 17(36), 33-44.

Lima, A. S., Barros, L., \& Enumo, S. R. F. (2014). Enfrentamento em crianças portuguesas hospitalizadas por câncer: comparação de dois instrumentos de avaliação. Estudos de Psicologia (Campinas), 31(4), 559-571. http://dx.doi. org/10.1590/0103-166X2014000400010

Ministério da Saúde (Brasil). Secretaria de Atenção à Saúde. Departamento de Atenção Especializada. (2013). Doença falciforme: condutas básicas para tratamento. Brasília: Autor.

Moraes, E. O., \& Enumo, S. R. F. (2008). Estratégias de enfrentamento da hospitalização em crianças avaliadas por instrumento informatizado. Psico-USF, 13(2) 221-231. http://dx. doi.org/10.1590/S1413-82712008000200009 
Motta, A. B., \& Enumo, S. R. F. (2010). Intervenção psicológica lúdica para o enfrentamento da hospitalização em crianças com câncer. Psicologia: Teoria e Pesquisa, 26(3), 445-454. http://dx.doi.org/10.1590/\$0102-37722010000300007

Motta, A. B., Perosa, G. B., Barros, L., Silveira, K. A, Lima, A. S. S., Carnier, L. E., ... Caprini, F. R. (2015). Comportamentos de coping no contexto da hospitalização infantil. Estudos de Psicologia (Campinas), 32(2), 331-341. http://dx.doi. org/10.1590/0103-166X2015000200016

Oliveira, C. G. T., Paula, K. M. P., \& Enumo, S. R. F. (2017). A psychological intervention proposal on coping with pain for children with Sickle Cell Disease. Estudos de Psicologia (Campinas), 34(3), 355-366. http://dx.doi.org/10.1590/1982-0 2752017000300004

Poveda, C. L. E. C., Silva, J. A., Passareli, P., Santos, J., \& Linhares, M. B. M. (2010). Instructions for administering the aces Pain Scale: Revised (FPS-R) in languages other than English. Pediatric Pain Sourcebook. Retrieved December 21, 2016, from www. painsourcebook.ca

Ramos, F. P., Enumo, S. R. F., \& Paula, K. M. P. (2015). Motivational Theory of Coping: A developmental proposal for the analysis of coping with stress. Estudos de Psicologia (Campinas), 32(2), 269-279. http://dx.doi.org/10.1590/0103-1 66X2015000200011

Sena, T. S., Vieira, C., \& Lyra, I. M. (2011). Fase aguda do acidente vascular encefálico na doença falciforme. Revista Baiana de Pediatria, 5(1), 54-55. http://dx.doi.org/10.1590/S1516-84842007000300013

Skinner, E. A., Edge, K., Altman, J., \& Sherwood, H. (2003). Searching for the structure of coping: A review and critique of category systems for classifying ways of coping. Pychological Bulletin, 129(2), 216-269. http://dx.doi.org/10.1037/0033-2 909.129.2.216

Skinner, E. A., \& Wellborn, J. G. (1994). Coping during childhood and adolescence: A motivacional perspective. In D. L. Featherman, R. M. Lerner, \& M. Perlmutter (Eds.), Life-Span Development and Behavior (Vol.12, pp.91-133). Hillsdale: Lawrence Erlbaum Associates.

Skinner, E. A., \& Zimmer-Gembeck, M. J. (2007). The development of coping. Annual Review of Psychology, 58, 119-144. http://dx.doi.org /10.1146/annurev.psych.58.110405.085705

Skinner, E. A., \& Zimmer-Gembeck, M. J. (2016). The development of coping: Stress, neurophysiology, social relationships, and resilience during childhood and adolescence. New York: Springer.

Stevens, B. J., Yamada, J., Estabrooks, C. A., Stinson, J., Campbell, F., Scott, S. D., \& Cummings, G. (2014). Pain in hospitalized children: Effect of a multidimensional knowledge translation strategy on pain process and clinical outcomes. Pain, 155(1), 60-68. http://dx.doi.org/10.1016/j.pain.2013.09.007

Vasconcelos, A. G., \& Nascimento, E. (2016). Teoria Motivacional do Coping: um modelo hierárquico e desenvolvimental. Avaliação Psicológica, 15(Esp.), 77-87. Recuperado em outubro 3, 2018, de http://pepsic.bvsalud.org/scielo. php?script=sci_arttext\&pid=S1677-047120160 00300009\&lng=pt\&tIng=pt

Von Baeyer, C. L., Stevens, B. J. S., Chambers, C. T., Craig, K. D., Finley, G. A., Grunau, R. E., ... McGrath, P. J. (2014). Training highly qualified health research personnel: The pain in child health consortium. Pain Research and Management, 19(5), 267-274.

Recebido: maio 6, 2016

Versão final: janeiro 2, 2017

Aprovado: março 30, 2017 